\title{
BMJ Open C reactive protein level as a marker for dyslipidaemia, diabetes and metabolic syndrome: results from the Korea National Health and Nutrition Examination Survey
}

Hyemin Jeong, ${ }^{1}$ Sun-Young Baek, ${ }^{2}$ Seon Woo Kim, ${ }^{2}$ Eun-Jung Park, ${ }^{3}$ Jaejoon Lee, ${ }^{4}$ Hyungjin Kim, ${ }^{4}$ Chan Hong Jeon ${ }^{\circ} 1$

To cite: Jeong H, Baek S-Y, Kim SW, et al. C reactive protein level as a marker for dyslipidaemia, diabetes and metabolic syndrome: results from the Korea National Health and Nutrition Examination Survey. BMJ Open 2019;9:e029861. doi:10.1136/ bmjopen-2019-029861

\section{- Prepublication history for} this paper is available online. To view these files, please visit the journal online (http://dx.doi. org/10.1136/bmjopen-2019009861).

$\mathrm{HK}$ and $\mathrm{CHJ}$ contributed equally.

Received 15 February 2019

Revised 16 June 2019

Accepted 11 July 2019

\section{Check for updates}

(c) Author(s) (or their employer(s)) 2019. Re-use permitted under CC BY-NC. No commercial re-use. See rights and permissions. Published by BMJ.

For numbered affiliations see end of article.

Correspondence to Chan Hong Jeon; chjeon@gmail.com

Hyungjin Kim; passiondoc@gmail.com

\section{ABSTRACT}

Objective Plasma $\mathrm{C}$ reactive protein (CRP) is a marker of inflammation, and increased plasma CRP is reported in many diseases, including cardiovascular disease, diabetes, metabolic syndrome, arthritis and malignancies. The aim of the study was to evaluate the association between plasma CRP levels and cardiovascular disease, metabolic syndrome, malignancies and other comorbidities.

Design A retrospective, cross-sectional survey study. Setting Large population survey in Korea.

Methods A total of 5887 (weighted $n=40251868$ ) participants aged 19 years or older from the 2016 Korea National Health and Nutrition Examination Survey were included for analysis. Weighted prevalence and $\mathrm{OR}$ of comorbidities were analysed according to the continuous variable of log plasma high-sensitivity CRP levels.

Results The mean age was $46.7 \pm 0.37$ years and the median plasma CRP was $0.58 \mathrm{mg} / \mathrm{L}$ (IQR 0.36-1.09). The mean plasma CRP levels were higher in participants with cardiovascular diseases and cardiovascular risk factors, osteoarthritis, rheumatoid arthritis, pulmonary tuberculosis, and several cancers, including gastric, colon, breast and cervix, than in the general population. In the multivariable analysis, plasma CRP concentration was associated with increased prevalence of hypertriglyceridaemia (OR 1.157, $95 \% \mathrm{Cl} 1.040$ to $1.287, \mathrm{p}=0.007$ ), diabetes (OR 1.204, $95 \% \mathrm{Cl} 1.058$ to $1.371, \mathrm{p}=0.005)$ and metabolic syndrome (OR 1.228, 95\% $\mathrm{Cl} 1.112$ to $1.357, \mathrm{p}<0.001$ ) after adjustment for socioeconomic and lifestyle characteristics. There was no significant association between plasma CRP level and cancers.

Conclusion Plasma CRP was associated with an increased risk of dyslipidaemia, diabetes and metabolic syndrome in the general population.

\section{INTRODUCTION}

Plasma $\mathrm{C}$ reactive protein (CRP) is an acutephase reactant produced by hepatocytes, and its production is regulated by interleukin-6 (IL-6) and other inflammatory cytokines. ${ }^{1}$ Plasma CRP is a useful non-specific biomarker, and plasma CRP measurement is

\section{Strengths and limitations of this study}

- This study analysed the association between plasma $C$ reactive protein (CRP) and comorbidities using nationwide representative samples of the Korean adult population.

- The study evaluated the socioeconomic and lifestyle characteristics relevant to comorbidities and adjusted for these factors in the analysis.

- Definition of myocardial infarction or angina, stroke, cancers, and other comorbidities depended on the information reported by participants during the interview.

- This study was unable to assess the use of medications, such as non-steroidal anti-inflammatory drugs or corticosteroids, that may have affected plasma CRP levels.

- This cross-sectional study may have potential unknown inherent biases and confounding factors.

used as a screening test for organic diseases, assessment of disease activity in inflammatory conditions such as rheumatological diseases, diagnosis and management of infection, and the differential diagnosis or classification of inflammatory diseases. ${ }^{1}$ Plasma CRP levels reflect the disease course of certain diseases, including infections, inflammatory disease, necrosis, trauma and malignancy. Plasma CRP measurement was found to be associated with increased risk of all-cause mortality in the Copenhagen City Heart Study, and this study revealed that a doubling of plasma CRP levels correlated with a 1.43-fold risk of cardiovascular mortality and a 1.38-fold risk of cancer mortality. ${ }^{2}$ Plasma CRP levels are also strongly associated with the risk of hypertension and coronary heart disease, stroke, and diabetes. ${ }^{3-6}$ Plasma CRP levels are also directly involved in vascular pathology via the 
activation of inflammatory cells, including macrophages, endothelial cells and vascular smooth muscle cells. ${ }^{7}$ Metabolic syndrome is a cluster of cardiovascular risk factors and is associated with the development of cardiovascular diseases (CVDs) and type 2 diabetes mellitus. Plasma CRP is associated with metabolic syndrome and its components. ${ }^{8}$ In addition, increased plasma CRP concentrations have been reported in many types of solid malignancies and lymphoma. ${ }^{9} 10$ Tumour growth causes tissue inflammation and subsequently increases production of inflammatory protein. Thus, plasma CRP could be an indicator of an immune response to tumour antigens. ${ }^{11}$

Evidence regarding the association between plasma CRP concentration and risk of major disease from studies involving large populations would be useful for routine clinical practice. However, the relationship between plasma CRP and overall comorbidities, including CVD, cancers and other comorbidities, has not been thoroughly investigated in the Korean population. In recent large-scale observational studies, the reported prevalence of metabolic syndrome, diabetes and hypertension was $27.4 \%, 11.4 \%$ and $30.3 \%$, respectively, in the Korean adult population. ${ }^{12-14}$ Therefore, it is important to recognise metabolic syndrome or cardiovascular risk factors in their early phase to promote public health. Plasma CRP may be a sensitive biochemical indicator in routine clinical practice. The purpose of this study was to evaluate the association between plasma CRP and comorbidities in the Korean adult population using a nationwide survey.

\section{MATERIALS AND METHODS Study population}

The Korea National Health and Nutrition Examination Survey (KNHANES) is a nationwide survey conducted periodically by the Korea Centers for Disease Control and Prevention to investigate the health and nutritional status of the Korean population. ${ }^{15}$ This survey assesses general health and nutrition status of individuals in South Korea through interviews about health and nutritional and basic health assessments. Participants were selected using the proportional allocation-systematic sampling method with multistage stratification to derive a representative Korean population. Although individual participants are not generally representative of the Korean population, this survey provided a representative estimates of the non-institutionalised Korean civilian population by using the power of sample weight. Every year, 10 000-12000 individuals in approximately $3800-4600$ households are selected from a panel based on the National Census Data. Participation rates of selected households in the past several cycles of the KNHANES have been high, from $75 \%$ to $80 \%$. This study analysed data from the 2016 KNHANES. In the 2016 KNHANES, 10806 individuals from 4416 households were selected and the participation rate was 75.4\%. Among 8150 participants in the 2016 KNHANES, 1768 participants were excluded as they were younger than 19 years of age. Of the remaining 6382 participants,
495 participants for whom serum plasma CRP levels were missing were excluded. Finally, a total of 5887 participants were selected for analysis.

\section{Demographic variables and data collection}

The KNHANES was conducted by four special research teams, each composed of eight experts including nurses, nutritionists and students majoring in public health. The selected professional investigator was placed at the investigation site after completing 1 month of education and practice. Subsequently, the ability to conduct research was verified through regular education and onsite quality management. A standardised interview was performed in participants' homes, and an established questionnaire was used to collect information on demographic variables and socioeconomic characteristics. Specifically, data on age, sex, income, region, education, marital status, alcohol consumption and smoking status were collected. Alcohol consumption was categorised into the following four groups based on the frequency of alcohol consumption during the past year: (1) never, (2) $\leq 1$ day/week, (3) 2-3 days/week and (4) $\geq 4$ days/week. Income level was categorised into quartiles based on the average individual monthly income. Urban and rural areas were classified by the administrative district. High physical activity was defined as continuous high-intensity sports, exercise or leisure activities that lasted more than 10 min for more than 3 days a week. If physical activity occurred less than 3 days a week, it was defined as low physical activity. Blood pressure (BP) was measured by nurses with a standard protocol. After at least $5 \mathrm{~min}$ of rest and with the participant in a sitting position, BP was measured on the right arm using a mercury sphygmomanometer. BP was measured three times and the mean of the second and third BP was calculated. The mean BP was used for analysis. Blood samples were collected from each participant after at least 8 hours of fasting. All blood samples were immediately refrigerated and transported in cold storage to the central testing facility. Plasma high-sensitivity CRP (subsequently referred to as plasma CRP throughout the manuscript) levels were measured by immunoturbidimetry (Roche Diagnostics, Penzberg, Germany) using Roche Cardiac C-Reactive Protein High Sensitive (Roche Diagnostics). Total cholesterol and triglyceride levels were measured using an enzymatic method with the Hitachi Automatic Analyzer 7600-210 (Hitachi, Tokyo, Japan). High-density lipoprotein (HDL) cholesterol levels were measured with a homogeneous enzymatic colourimetric method using the Hitachi Automatic Analyzer 7600-210 (Hitachi). Glucose levels were measured using a hexokinase ultraviolet method with the Hitachi Automatic Analyzer 7600-210 (Hitachi). Low-density lipoprotein (LDL) was calculated using the Friedewald formula: LDL cholesterol=total cholesterol - HDL cholesterol - triglyceride $/ 5{ }^{16}$ Height and weight were assessed using standardised techniques and equipment. Briefly, height was measured to the nearest $0.1 \mathrm{~cm}$ using a portable stadiometer Seca 225 (Seca, Hamburg, Germany). Weight was measured to the 
nearest $0.1 \mathrm{~kg}$ using a GL-6000-20 (G-tech, Gyenggi-do, Korea). Body mass index (BMI) was calculated as weight divided by height squared $\left(\mathrm{kg} / \mathrm{m}^{2}\right)$. For measurement of waist circumference, participants were asked to breathe out, and the waist girth at the midpoint between the lower margin of the ribs and the iliac crest was measured to the nearest $0.1 \mathrm{~cm}$ using the Seca 200 (Seca).

\section{Definition of comorbidities}

Definitions of hypertension, prehypertension, diabetes, impaired fasting glucose, hypercholesterolaemia and hypertriglyceridaemia were taken from the KNHANES. ${ }^{15}$ Hypertension was defined as a mean systolic BP (SBP) $\geq 140 \mathrm{~mm} \mathrm{Hg}$ or diastolic BP (DBP) $\geq 90 \mathrm{~mm} \mathrm{Hg}$ or the use of antihypertensive agents. Prehypertension was defined as an average SBP of $120-139 \mathrm{~mm} \mathrm{Hg}$ or a DBP of $80-89 \mathrm{~mm} \mathrm{Hg}$. Diabetes mellitus was defined as a fasting plasma glucose $\geq 126 \mathrm{mg} / \mathrm{dL}$ and/or current use of antidiabetic drugs or insulin due to a previous diagnosis of diabetes. Impaired fasting glucose was defined by a range of fasting plasma glucose levels of $100 \mathrm{mg} / \mathrm{dL}$ to $<126 \mathrm{mg} / \mathrm{dL}$. Diagnosis of hypercholesterolaemia was defined as a total plasma cholesterol level of $\geq 240 \mathrm{mg}$ / $\mathrm{dL}$ after 8 hours of fasting or current use of cholesterol-lowering agents. Hypertriglyceridaemia was defined as a triglyceride level of $>200 \mathrm{mg} / \mathrm{dL}$ after 12 hours of fasting. Metabolic syndrome was defined according to the modified National Cholesterol Education Program Adult Treatment Panel III (ATP III) definition. ${ }^{17}$ Current ATP III criteria define metabolic syndrome as the presence of any three of the following five traits: (1) central obesity (waist circumference $\geq 90 \mathrm{~cm}$ in Asian men or $\geq 80 \mathrm{~cm}$ in Asian women), (2) hypertriglyceridaemia (fasting serum triglycerides $\geq 150 \mathrm{mg} / \mathrm{dL}$ or drug treatment for elevated triglycerides), (3) decreased HDL cholesterol (serum HDL cholesterol $<40 \mathrm{mg} / \mathrm{dL}$ in men and $<50 \mathrm{mg} / \mathrm{dL}$ in women or drug treatment for low HDL cholesterol), (4) elevated BP ( $\mathrm{SBP} \geq 130 \mathrm{~mm} \mathrm{Hg}$ and/or DBP $\geq 85 \mathrm{~mm}$ $\mathrm{Hg}$ or drug treatment for elevated $\mathrm{BP}$ ), and (5) hyperglycaemia (fasting plasma glucose $\geq 100 \mathrm{mg} / \mathrm{dL}$ or drug treatment for elevated blood glucose). Stroke was defined in the questionnaire as 'stroke diagnosed by a physician' through a standardised interview. We asked 'Was your stroke diagnosed by a physician?' and there were three possible responses ('Yes', 'No' and 'I have never been sick before'). Participants who chose 1 (yes) were classified into the stroke group. Each interview was conducted individually by a trained professional investigator. Other comorbidities were defined in the same way as the stroke diagnosis. Information was collected on other comorbidities diagnosed by a physician, including myocardial infarction or angina, osteoarthritis, rheumatoid arthritis, osteoporosis, pulmonary tuberculosis, asthma, thyroid disease, atopic dermatitis, and allergic rhinitis. Information on malignancies diagnosed by a physician, including gastric cancer, breast cancer, cervical cancer, lung cancer and thyroid cancer, was also collected.

\section{Statistical analyses}

To reflect representative estimates of the non-institutionalised Korean civilian population, survey sample weights were applied in the analyses. Sample weights were calculated by considering the sampling rate, response rate and age/sex proportions of the reference population (2005 Korean National Census Registry). Because the distribution of plasma CRP was highly skewed, log-transformed plasma CRP was used for analyses. To analyse the effect of plasma CRP on morbidity, univariable logistic regression models were computed with comorbidities as dependent variables and log plasma CRP level as an independent variable. Variables associated with $\mathrm{p}$ value outcomes $\leq 0.05$ in univariable analysis were included in the multivariable analysis. Multivariable logistic regression analysis was performed with adjustments for age, income, region, education, marriage, smoking, alcohol consumption, BMI and physical activity. The strength of associations was estimated using ORs and 95\% CIs. Multivariable linear regression analysis was used to estimate the association between metabolic syndrome and plasma CRP levels. A receiver operating characteristics (ROC) curve was used to analyse the specificity, sensitivity, and negative and positive predictive values of plasma CRP for metabolic syndrome, hypertriglyceridaemia and diabetes. The maximum value of the Youden's index was selected as the optimum cut-off point. Statistical analyses were performed using SAS V.9.4. All $p$ values were two-sided, and a $p$ value $<0.05$ was considered statistically significant.

\section{Patient and public involvement}

The KNHANES data were released after anonymisation. The study population was not involved in the design of this study.

\section{RESULTS}

The clinical characteristics of the study population are shown in table 1 . The mean age was $46.7 \pm 0.37$ years, and $50.3 \%$ of the population were male. The mean plasma CRP level of the study population was $1.23 \pm 0.03 \mathrm{mg} / \mathrm{L}$ and the median plasma CRP concentration was $0.58 \mathrm{mg} / \mathrm{L}$ (IQR 0.36-1.09). Distribution of plasma CRP was markedly skewed, and $91.3 \%$ of participants had a plasma CRP $\leq 3 \mathrm{mg} / \mathrm{L}$. The mean concentration of plasma CRP according to each of the comorbidities is presented in figure 1. Mean plasma CRP levels were higher in participants with CVDs and cardiovascular risk factors, osteoarthritis, rheumatoid arthritis, pulmonary tuberculosis, and several cancers, including gastric, colon, breast and cervix, than in the general population. The mean plasma CRP was significantly higher in subjects with CVDs and cardiovascular risk factors than in those without CVDs or cardiovascular risk factors (table 2). In the univariable analysis, increased log plasma CRP was significantly associated with an increased probability of stroke, myocardial infarction or angina, hypercholesterolaemia, hypertriglyceridaemia, diabetes, hypertension, and metabolic syndrome. 
Table 1 Demographic, clinical and laboratory characteristics of the study population

\begin{tabular}{ll}
\hline Variables & $\begin{array}{l}\text { Value (unweighted } \mathbf{n = 5 8 8 7} \\
\text { weighted } \mathbf{n = 4 0} \mathbf{2 5 1} \mathbf{8 6 9})\end{array}$ \\
\hline Age, years & $46.74 \pm 0.37$ \\
Male & $2568(50.3)$ \\
\hline Income & \\
\hline Low & $1464(25.8)$ \\
\hline Mid-low & $1468(24.4)$ \\
\hline Mid-high & $1476(25.0)$ \\
\hline High & $1458(24.8)$ \\
\hline Education & \\
\hline Elementary school & $1189(15.1)$ \\
\hline Middle school & $576(9.1)$ \\
\hline High school & $1794(36.2)$ \\
\hline College graduation & $2045(39.6)$ \\
\hline Marital status & \\
\hline Married & $4970(77.3)$ \\
\hline Not married & $917(22.7)$ \\
\hline
\end{tabular}

Region

\begin{tabular}{|c|c|}
\hline Urban & $4740(84.3)$ \\
\hline Rural & $1147(15.7)$ \\
\hline \multicolumn{2}{|l|}{ Alcohol consumption } \\
\hline Never & $1610(22.9)$ \\
\hline$\leq 1$ day/week & $2889(52.7)$ \\
\hline 2-3 days/week & $877(16.8)$ \\
\hline$\geq 4$ days/week & $418(7.6)$ \\
\hline \multicolumn{2}{|l|}{ Smoking } \\
\hline Never smoked & $3490(56.2)$ \\
\hline Ex-smoker & $1204(20.9)$ \\
\hline Current smoker & 1098 (22.9) \\
\hline \multicolumn{2}{|l|}{ Physical activity } \\
\hline Low & $5258(92.2)$ \\
\hline High & $357(7.8)$ \\
\hline Body mass index $\left(\mathrm{kg} / \mathrm{m}^{2}\right)$ & $24.0 \pm 0.1$ \\
\hline Fasting glucose (mg/dL) & $100.4 \pm 0.4$ \\
\hline Total cholesterol (mg/dL) & $193.1 \pm 0.6$ \\
\hline HDL cholesterol (mg/dL) & $51.1 \pm 0.2$ \\
\hline LDL cholesterol (mg/dL) & $113.9 \pm 0.6$ \\
\hline Triglyceride (mg/dL) & $144.8 \pm 2.8$ \\
\hline Antihypertensive agents users & $1333(17.9)$ \\
\hline Lipid-lowering agents users & $664(9.2)$ \\
\hline $\begin{array}{l}\text { Oral hypoglycaemic agents or } \\
\text { insulin users }\end{array}$ & $549(7.4)$ \\
\hline $\begin{array}{l}\text { Plasma } C \text { reactive protein }(\mathrm{mg} / \mathrm{L}) \text {, } \\
\text { median (IQR) }\end{array}$ & $1.23 \pm 0.03,0.58(0.36-1.09)$ \\
\hline
\end{tabular}

Values are presented as mean \pm SD or unweighted $\mathrm{n}$ (weighted \%). HDL, high-density lipoprotein; LDL, low-density lipoprotein.

As the log plasma CRP value increased, the likelihood of metabolic syndrome increased, and the OR was 1.71. Increased log plasma CRP was significantly associated with increased prevalence of osteoarthritis, osteoporosis, pulmonary tuberculosis and allergic rhinitis (table 3). There was no association between solid malignancy and log plasma CRP level. In the multivariable analysis, increased log plasma CRP was significantly associated with increased prevalence of hypertriglyceridaemia, diabetes, impaired fasting glucose, metabolic syndrome and pulmonary tuberculosis after adjustment for age, sex, income, region, education, alcohol consumption, BMI, smoking and physical activity (table 4). Stroke, myocardial infarction or angina, and hypertension were not significantly associated with log plasma CRP level after adjustment. Multivariable linear regression was performed to inspect the association between plasma CRP levels and individual components of metabolic syndrome and lipid profiles (table 5). A number of components of metabolic syndrome were positively associated with log plasma CRP. Fasting glucose, triglyceride and waist circumference were positively associated with log plasma CRP level after adjustment for age, income, region, education, marital status, smoking, alcohol consumption, BMI and physical activity. Total cholesterol and LDL cholesterol were positively associated with plasma CRP level, and HDL cholesterol was negatively associated with log plasma CRP level.

ROC curve analysis was performed to evaluate the diagnostic value of serum plasma CRP concentration for metabolic syndrome, hypertriglyceridaemia and diabetes. A plasma CRP concentration cut-off value of $>0.54 \mathrm{mg} / \mathrm{L}$ showed $68.5 \%$ sensitivity, $56.6 \%$ specificity, $48.1 \%$ positive predictive value, $75.4 \%$ negative predictive value and $61.0 \%$ accuracy for metabolic syndrome. In hypertriglyceridaemia, a plasma CRP concentration cut-off value of $0.56 \mathrm{mg} / \mathrm{L}$ had $70.8 \%$ sensitivity, $51.3 \%$ specificity, $20.8 \%$ positive predictive value, $90.6 \%$ negative predictive value and $54.3 \%$ accuracy. In diabetes, a plasma CRP concentration cut-off value of $>0.53 \mathrm{mg} / \mathrm{L}$ showed $67.7 \%$ sensitivity, $48.9 \%$ specificity, $16.3 \%$ positive predictive value, $91.1 \%$ negative predictive value and $51.3 \%$ accuracy. Based on the cut-off value of metabolic syndrome ascertained by the ROC curve analysis, we defined lower inflammation as a plasma CRP concentration of $<0.54 \mathrm{mg} / \mathrm{L}$ and higher inflammation as a plasma CRP concentration of $\geq 0.54 \mathrm{mg} / \mathrm{L}$. Table 6 shows the prevalence of cardiovascular risk factors, metabolic syndrome, comorbidities and cancer according to lower and higher inflammation. The prevalence of stroke, hypercholesterolaemia, hypertriglyceridaemia, diabetes, impaired fasting glucose, hypertension, prehypertension, metabolic syndrome, osteoarthritis, osteoporosis and thyroid disease was significantly higher in the higher inflammation group than in the lower inflammation group.

\section{DISCUSSION}

We investigated the relationship between plasma CRP and overall comorbidities in the Korean adult population. We determined that elevated plasma CRP level was significantly associated with the increase in the prevalence of 


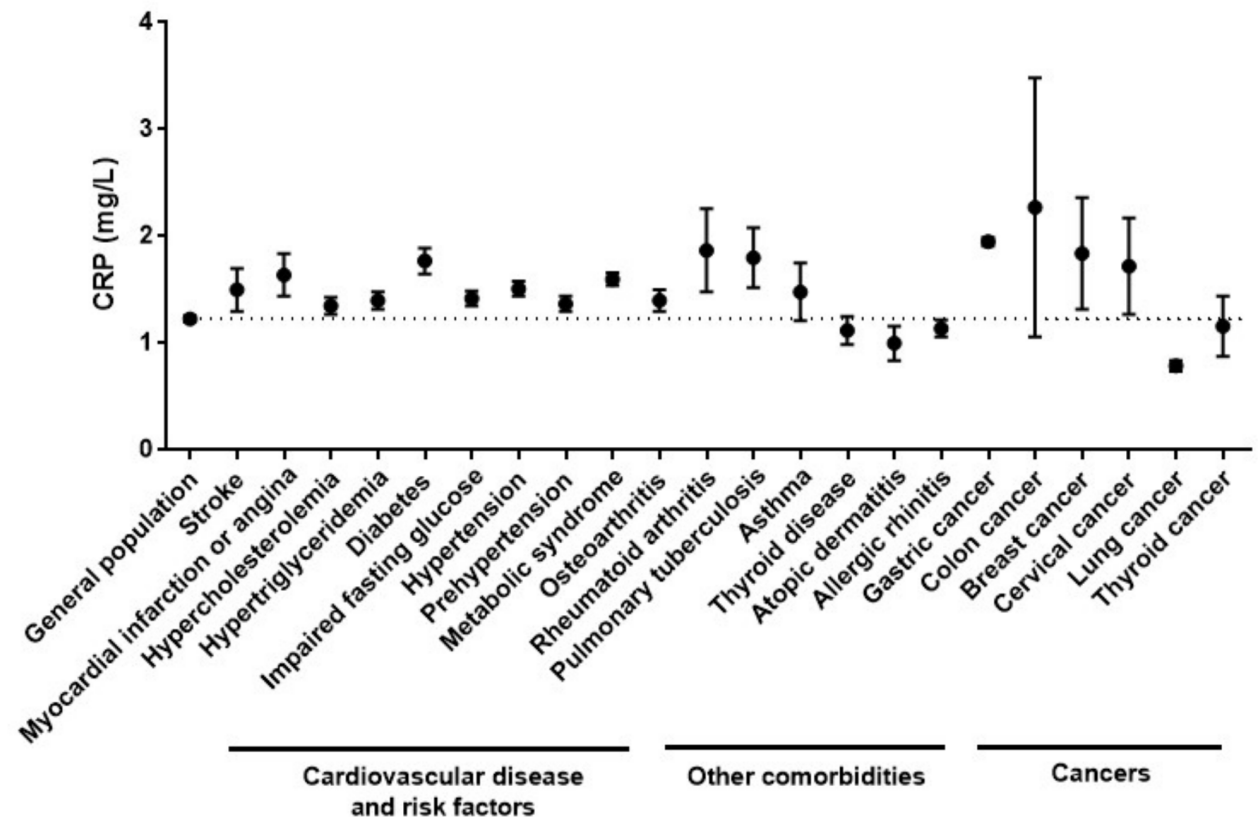

Figure 1 Mean plasma $\mathrm{C}$ reactive protein (CRP) concentration according to cardiovascular diseases and cardiovascular risk factors, other comorbidities, and cancers. The dotted line represents mean plasma CRP concentration of the total subjects included in the study.

dyslipidaemia, diabetes and metabolic syndrome. Plasma CRP was not associated with solid malignancy after adjustment for age, income, region, education, marital status, smoking, alcohol consumption, BMI and physical activity in this study. In this study, the median plasma CRP was $0.58 \mathrm{mg} / \mathrm{L}$ (IQR 0.36-1.09). In the Copenhagen General Population Study of 63500 individuals, the median plasma CRP concentration was $1.53 \mathrm{mg} / \mathrm{L}(\mathrm{IQR} 1.14-2.51){ }^{18}$ In the US National Health and Nutrition Examination Survey (NHANES) that included 21004 participants, the mean plasma CRP was $4.3 \pm 7.7 \mathrm{mg} / \mathrm{L}$, and the median was $2.1 \mathrm{mg} / \mathrm{L}$ (IQR 0.8-4.7) ${ }^{19}$ The mean plasma CRP concentration in the Korean adult population seems to be lower than that of the Western population. Considering plasma CRP is strongly correlated with BMI, ${ }^{20}$ lower mean plasma CRP levels in the Korean population may be due to relatively lower BMI in Asian people compared with people in Western countries. Plasma CRP levels closely correlate with mean BMI at a population level across ethnic groups. ${ }^{21}$ However, obesity does not completely explain the plasma CRP levels. Race and gender differences exist in the distribution of plasma CRP. ${ }^{22}$ Genome-wide association studies using the Women's Health Initiative SNP Health Association Resource reported the ancestry-specific genetic variants associated with plasma CRP concentration. ${ }^{23}$ East Asian ancestry was associated with lower age and lower BMI-adjusted plasma CRP compared with African-American ancestry. The TREM2 (triggering receptors expressed by the myeloid cells 2) variant associated with higher plasma CRP is common in AfricanAmerican individuals, but is much less common in Asian populations.

We determined that an increased plasma CRP level was associated with increased odds of diabetes and impaired fasting glucose. Plasma CRP level was positively associated with fasting glucose level in this study. The NHANES revealed that plasma CRP level was elevated in participants with diabetes compared with those with normal fasting glucose in the US adult population. ${ }^{24}$ Elevated plasma CRP concentration was positively associated with haemoglobin A1c levels in patients with diabetes. ${ }^{25}$ Subjects with elevated acute-phase proteins were more likely to develop type 2 diabetes in the Insulin Resistance Atherosclerosis Study. ${ }^{26}$ Hyperglycaemia may contribute to inflammation by inducing endothelial dysfunction and stimulating reactive oxygen species generation. ${ }^{27}{ }^{28}$ Elevated plasma CRP was significantly associated with increased mean fasting insulin concentration. ${ }^{29}$ Plasma CRP induces endothelial insulin resistance and dysfunction through the spleen tyrosine kinase and RhoA-activation signalling pathway. ${ }^{30}$ The results of this study suggest an association between glycaemic control and systemic inflammation. Although we could not infer the cause and effect relationship due to the cross-sectional design, our findings indicate that chronic systemic inflammation may be of aetiological significance in insulin resistance and diabetes.

This study determined that plasma CRP was related to metabolic syndrome. US nationwide data revealed that participants with metabolic syndrome had significantly elevated plasma CRP levels compared with participants without metabolic syndrome in the NHANES III. ${ }^{31}$ Numerous studies have now confirmed that plasma CRP levels are elevated in patients with metabolic syndrome. ${ }^{32}$ We determined that plasma CRP was positively associated with a number of metabolic syndrome components. This finding corresponds well with previous studies that have found that mean levels of plasma CRP increased according to the increased number of metabolic 
Table 2 Plasma mean CRP levels according to the presence of cardiovascular disease and cardiovascular risk factors and the OR of each comorbidity according to log plasma CRP levels

\begin{tabular}{|c|c|c|c|c|c|}
\hline Variables & $\mathbf{n}$ & Plasma CRP (mg/L), mean \pm SE & $P$ value & OR $(95 \% \mathrm{Cl})$ & $P$ value \\
\hline Stroke & & & 0.174 & & 0.019 \\
\hline Yes & 121 & $1.50 \pm 0.20$ & & 1.24 (1.04 to 1.48$)$ & \\
\hline No & 5523 & $1.22 \pm 0.03$ & & Ref & \\
\hline $\begin{array}{l}\text { Myocardial infarction or } \\
\text { angina }\end{array}$ & & & 0.042 & & 0.010 \\
\hline Yes & 165 & $1.64 \pm 0.20$ & & 1.28 (1.06 to 1.54$)$ & \\
\hline No & 5475 & $1.21 \pm 0.03$ & & Ref & \\
\hline Hypercholesterolaemia & & & 0.089 & & $<0.001$ \\
\hline Yes & 1209 & $1.35 \pm 0.08$ & & $1.12(1.10$ to 1.30$)$ & \\
\hline No & 4481 & $1.20 \pm 0.04$ & & Ref & \\
\hline Hypertriglyceridaemia & & & 0.013 & & $<0.001$ \\
\hline Yes & 677 & $1.40 \pm 0.08$ & & $1.46(1.33$ to 1.59$)$ & \\
\hline No & 3729 & $1.18 \pm 0.04$ & & Ref & \\
\hline Glucose & & & $<0.001$ & & $<0.001$ \\
\hline Diabetes & 744 & $1.77 \pm 0.12$ & & 1.67 (1.51 to 1.84$)$ & \\
\hline Impaired fasting glucose & 1385 & $1.42 \pm 0.07$ & & 1.45 (1.34 to 1.56$)$ & \\
\hline Normal & 3561 & $1.06 \pm 0.04$ & & Ref & \\
\hline Blood pressure & & & $<0.001$ & & $<0.001$ \\
\hline Hypertension & 1909 & $1.51 \pm 0.07$ & & 1.64 (1.51 to 1.78$)$ & \\
\hline Prehypertension & 1409 & $1.37 \pm 0.07$ & & 1.41 (1.31 to 1.52$)$ & \\
\hline Normal & 2552 & $0.99 \pm 0.04$ & & Ref & \\
\hline Metabolic syndrome & & & $<0.001$ & & $<0.001$ \\
\hline Yes & 2193 & $1.60 \pm 0.06$ & & 1.71 (1.59 to 1.85$)$ & \\
\hline No & 3694 & $1.04 \pm 0.04$ & & Ref & \\
\hline
\end{tabular}

CRP, C reactive protein; Ref, reference.

syndrome components. ${ }^{33-36}$ Among metabolic syndrome components, hyperglycaemia, low HDL, hypertriglyceridaemia and central obesity were associated with plasma CRP in this study. BP was not significantly associated with plasma CRP. Previous studies reported that plasma CRP was significantly associated with all metabolic syndrome components, and among those components central obesity revealed the strongest association with plasma CRP levels. ${ }^{33}$ In a centrally obese population, waist circumference and triglycerides were significantly associated with plasma CRP after adjustment for age, smoking status, alcohol consumption and other metabolic syndrome components. ${ }^{8} \mathrm{BP}$ and HDL were not significantly associated with plasma CRP. These findings indicate that metabolic syndrome and a variety of components of metabolic syndrome are associated with low-grade systemic inflammation. The mechanisms of proinflammatory status and metabolic syndrome are not yet fully understood. Adipocytes release tumour necrosis factor- $\alpha$ and IL-6 into circulation in patients with metabolic syndrome, and they stimulate plasma CRP production in the liver and induce insulin resistance. ${ }^{37}{ }^{38}$ Plasma CRP is also released in the adipocytes of body fat, and plasma CRP is independently associated with total body fat, central fat and insulin resistance. ${ }^{39}$ Besides, in a genome-wide association study among 6345 healthy women, it was reported that seven loci were associated with plasma CRP levels. ${ }^{40}$ Protein products of six of these seven loci are directly involved in metabolic syndrome, insulin resistance, beta cell function, weight homeostasis and/or premature atherosclerosis. Common variations in several genes involved in metabolic and inflammatory regulation have significant effects on plasma CRP levels. The results of these studies suggest plasma CRP may be a useful biomarker of vascular disease and diabetes.

Metabolic syndrome is associated with incident CVD and diabetes. ${ }^{41}$ Men with metabolic syndrome show significantly increased cardiovascular mortality, even in the absence of baseline CVD and diabetes. ${ }^{42}$ Although plasma CRP was associated with diabetes and metabolic syndrome, plasma CRP was not significantly associated with stroke and myocardial infarction or angina after adjustment for age, income, region, education, marital status, smoking, alcohol consumption, BMI and physical 
Table 3 Plasma mean CRP levels according to the presence of other medical comorbidities and solid cancers and OR for each comorbidity according to log plasma CRP levels

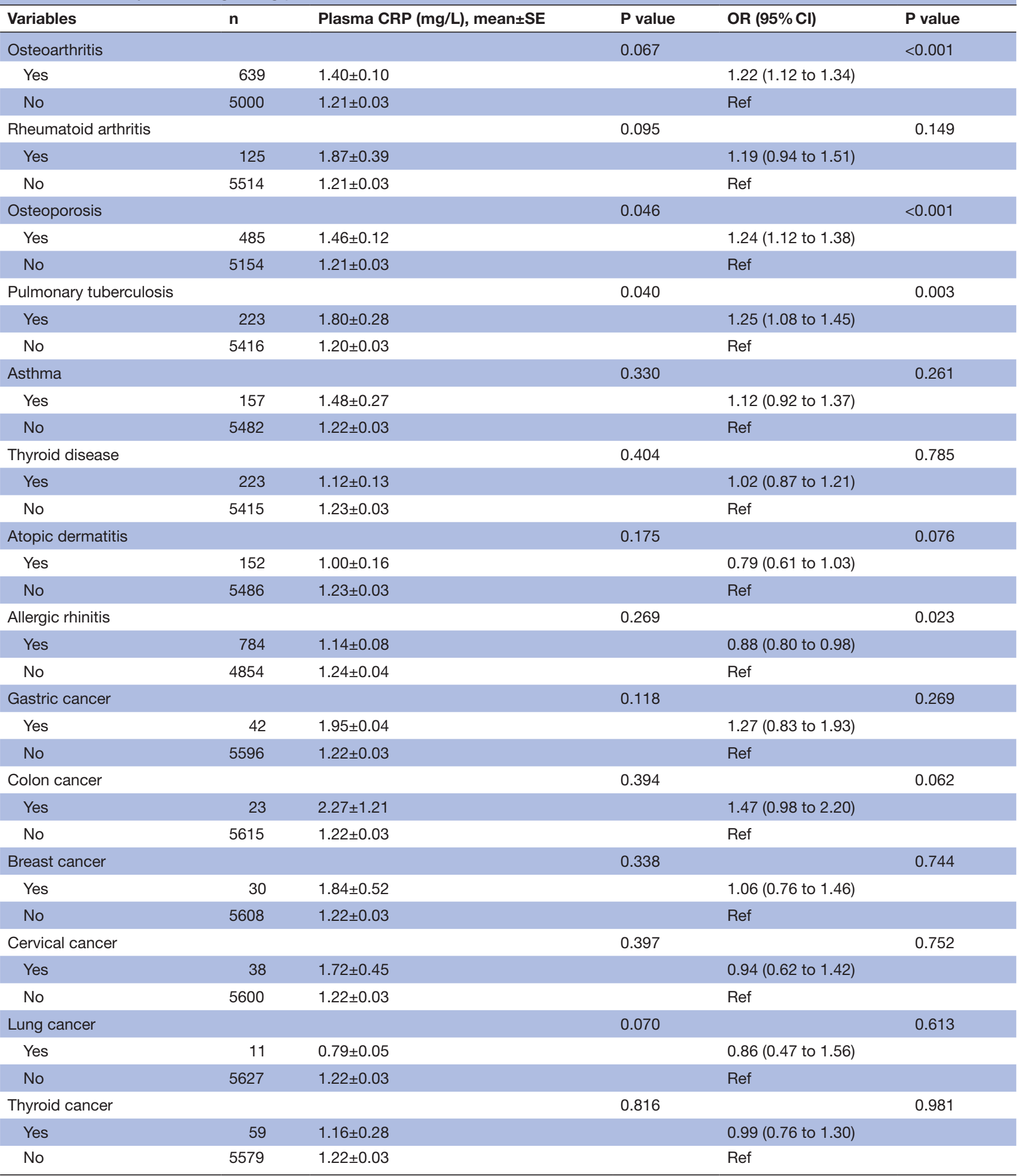

CRP, C reactive protein; Ref, reference.

activity in this study. However, previous studies reported that plasma CRP is an independent risk factor for atherosclerosis, atherothrombosis, hypertension and myocardial infarction. ${ }^{43-46}$ Inflammation plays a key role in the development of atherosclerosis. ${ }^{47}$ Plasma CRP may be involved in all phases of atherosclerosis by direct proinflammatory 
Table 4 Multivariable logistic regression analysis for OR and $95 \% \mathrm{Cl}$ of comorbidities according to log plasma C reactive protein levels

\begin{tabular}{|c|c|c|}
\hline Variables & OR $(95 \% \mathrm{Cl})$ & $P$ value \\
\hline Stroke & $0.902(0.730$ to 1.115$)$ & 0.337 \\
\hline $\begin{array}{l}\text { Myocardial infarction or } \\
\text { angina }\end{array}$ & 0.949 (0.743 to 1.212$)$ & 0.673 \\
\hline Hypercholesterolaemia & 0.999 (0.980 to 1.112$)$ & 0.989 \\
\hline Hypertriglyceridaemia & 1.157 (1.040 to 1.287$)$ & 0.007 \\
\hline Diabetes & 1.204 (1.058 to 1.371$)$ & 0.005 \\
\hline Impaired fasting glucose & 1.117 (1.016 to 1.229$)$ & 0.022 \\
\hline Hypertension & $1.083(0.978$ to 1.200$)$ & 0.126 \\
\hline Prehypertension & 1.074 (0.992 to 1.162$)$ & 0.078 \\
\hline Metabolic syndrome & $1.146(1.035$ to 1.270$)$ & 0.009 \\
\hline Osteoarthritis & 0.952 (0.834 to 1.086$)$ & 0.461 \\
\hline Osteoporosis & 1.087 (0.945 to 1.252$)$ & 0.240 \\
\hline Pulmonary tuberculosis & $1.187(1.017$ to 1.386$)$ & 0.029 \\
\hline Allergic rhinitis & $1.006(0.905$ to 1.118$)$ & 0.910 \\
\hline
\end{tabular}

Adjusted for age, sex, income, region, education, marital status, alcohol consumption, body mass index, smoking, marital status and physical activity.

effects via complement activation, apoptosis, vascular cell activation, monocyte recruitment, lipid accumulation and thrombosis. ${ }^{48}$ In this study, while the definitions of diabetes, dyslipidaemia and metabolic syndrome were based on the laboratory test results, the diagnoses of myocardial infarction, angina and stroke depended on the information provided by the participants during the

Table 5 Association between log plasma $\mathrm{C}$ reactive protein level and individual components of metabolic syndrome and lipid profiles in multivariable linear regression analysis

\begin{tabular}{lccc}
\hline Variables & $\boldsymbol{\beta}$ & SE & P value \\
\hline $\begin{array}{l}\text { Number of metabolic syndrome } \\
\text { component }\end{array}$ & 0.104 & 0.024 & $<0.001$ \\
\hline $\begin{array}{l}\text { Individual component } \\
\text { Fasting glucose (mg/dL) }\end{array}$ & 0.014 & 0.003 & $<0.001$ \\
\hline HDL cholesterol (mg/dL) & -1.714 & 0.237 & $<0.001$ \\
\hline Triglyceride (mg/dL) & 0.043 & 0.010 & $<0.001$ \\
\hline Waist circumference (cm) & 0.463 & 0.077 & $<0.001$ \\
$\begin{array}{l}\text { Systolic blood pressure (mm } \\
\text { Hg) }\end{array}$ & 0.405 & 0.253 & 0.112 \\
$\begin{array}{l}\text { Diastolic blood pressure (mm } \\
\text { Hg) }\end{array}$ & 0.179 & 0.179 & 0.320 \\
\hline $\begin{array}{l}\text { Total cholesterol (mg/dL) } \\
\text { LDL cholesterol (mg/dL) }\end{array}$ & 1.939 & 0.735 & 0.009 \\
\hline
\end{tabular}

Adjusted for age, sex, income, region, education, marital status, alcohol consumption, body mass index, smoking, marital status and physical activity.

HDL, high-density lipoprotein; LDL, low-density lipoprotein. interview. Although the interview was conducted individually by a trained professional investigator, recall bias should be considered.

We analysed cut-off values for metabolic syndrome, as well as hypertriglyceridaemia and diabetes. The plasma CRP cut-off value for metabolic syndrome was $0.54 \mathrm{mg} / \mathrm{L}$ with $68.5 \%$ sensitivity and $48.1 \%$ specificity. The plasma CRP concentration was likely to be low because this was a study of the general population rather than hospitalised patients. The Centers for Disease Control and Prevention and the American Heart Association suggested that levels of $\geq 3 \mathrm{mg} / \mathrm{L}$ be used to determine high cardiovascular risk. ${ }^{49}$ However, low levels of plasma CRP also provide important prognostic information on the cardiovascular risk. Ridker and $\operatorname{Cook}^{50}$ reported that the predictive value of plasma CRP for cardiovascular events is linear across a full range of values, including low levels of plasma CRP. Cardiovascular risk was very low for individuals at the end of the spectrum with plasma CRP levels $<0.5 \mathrm{mg} / \mathrm{L}$. In participants with plasma CRP levels between 0.5 and $1.0 \mathrm{mg} / \mathrm{L}$, the relative risk of cardiovascular event was 1.6 (95\% CI 1.1 to 2.5$)$ when compared with those with plasma CRP levels $<0.5 \mathrm{mg} / \mathrm{L}$ after adjustment for Framingham Risk Score and additionally for diabetes. The cut-off values for hypertriglyceridaemia and diabetes were $0.56 \mathrm{mg} / \mathrm{L}$ and $0.53 \mathrm{mg} / \mathrm{L}$, respectively. In hypertriglyceridaemia and diabetes, the sensitivity of the cut-off value was about $70 \%$ and the specificity was about $50 \%$, which were similar to that of metabolic syndrome. This sensitivity is not very high $(70 \%)$ and the specificity is low (50\%). Therefore, the incorporation of plasma CRP into the diagnostic criteria for metabolic syndrome or cardiovascular risk factors is not suggested, based on the results of the current study. More studies on plasma CRP and other inflammatory markers are needed. However, these results suggest that people with completely normal plasma CRP levels are less likely to have metabolic syndrome, hypertriglyceridaemia and diabetes.

In this study, there was no association between plasma CRP and malignancy. Many case-control studies and prospective studies have demonstrated that plasma CRP is associated with increased cancer risks. ${ }^{51-54}$ In a prospective study from Greece, 496 cases of cancer and 996 controls were analysed. This study reported higher plasma CRP levels in patients with cancer compared with controls. Plasma CRP levels have a strong association with the risk of cancers, including liver, lung, skin, kidney, bladder cancer and lymphoma/leukaemia, compared with other types of malignancy. ${ }^{53}$ A Danish general population study of 10408 individuals observed for up to 16 years showed that a baseline plasma CRP level more than $3 \mathrm{mg} / \mathrm{L}$ was associated with a 1.3-fold increased risk of any type of cancer compared with individuals with a plasma CRP level less than $1 \mathrm{mg} / \mathrm{L} .{ }^{54}$ However, other studies reported no significant association between plasma CRP and cancer. ${ }^{55-57}$ In a US study of 28345 healthy women aged 45 years or older who were followed prospectively, baseline plasma CRP was a reliable marker of risk of future CVD, but not 
Table 6 Prevalence of cardiovascular risk factors, metabolic syndrome, comorbidities and cancer according to lower and higher inflammation

\begin{tabular}{|c|c|c|c|c|}
\hline Variables & $\mathbf{n}$ & $\begin{array}{l}\text { Lower inflammation } \\
\text { (plasma CRP <0.54 mg/L) }\end{array}$ & $\begin{array}{l}\text { Higher inflammation } \\
\text { (plasma CRP } \geq 0.54 \mathrm{mg} / \mathrm{L} \text { ) }\end{array}$ & $P$ value \\
\hline Stroke & 121 & $41(1.31)$ & $80(2.03)$ & 0.037 \\
\hline Myocardial infarction or angina & & $68(1.99)$ & $97(2.40)$ & 0.332 \\
\hline Hypercholesterolaemia & 1209 & $540(16.58)$ & $699(21.57)$ & $<0.001$ \\
\hline Hypertriglyceridaemia & 677 & $194(9.83)$ & $483(22.15)$ & $<0.001$ \\
\hline Diabetes & 744 & $243(7.36)$ & $501(14.06)$ & $<0.001$ \\
\hline Impaired fasting glucose & 1385 & $504(17.48)$ & $881(28.85)$ & $<0.001$ \\
\hline Hypertension & 1909 & $681(20.87)$ & $1228(34.85)$ & $<0.001$ \\
\hline Prehypertension & 1409 & $640(24.32)$ & $769(26.96)$ & $<0.001$ \\
\hline Metabolic syndrome & 2193 & $684(21.81)$ & $1509(44.60)$ & $<0.001$ \\
\hline Osteoarthritis & 639 & $250(6.83)$ & $389(10.11)$ & $<0.001$ \\
\hline Rheumatoid arthritis & 125 & $59(1.76)$ & $66(1.68)$ & 0.793 \\
\hline Osteoporosis & 485 & $186(4.76)$ & $299(7.35)$ & $<0.001$ \\
\hline Pulmonary tuberculosis & 223 & $81(2.91)$ & $142(4.31)$ & 0.014 \\
\hline Asthma & 157 & $64(2.48)$ & $93(2.84)$ & 0.483 \\
\hline Thyroid disease & 223 & 114 (3.33) & 109 (3.29) & 0.007 \\
\hline Atopic dermatitis & 152 & $81(4.03)$ & $71(2.83)$ & 0.053 \\
\hline Allergic rhinitis & 784 & $390(16.25)$ & 391 (14.42) & 0.117 \\
\hline Gastric cancer & 42 & $20(0.48)$ & $22(0.56)$ & 0.654 \\
\hline Colon cancer & 23 & $8(0.17)$ & $15(0.31)$ & 0.252 \\
\hline Breast cancer & 30 & $15(0.47)$ & $15(0.38)$ & 0.608 \\
\hline Cervical cancer & 38 & $20(0.70)$ & $18(0.45)$ & 0.215 \\
\hline Lung cancer & 11 & $4(0.10)$ & $7(0.19)$ & 0.268 \\
\hline Thyroid cancer & 59 & $27(0.96)$ & $32(0.92)$ & 0.906 \\
\hline
\end{tabular}

Values are presented as unweighted $\mathrm{n}$ (weighted \%). CRP, C reactive protein.

cancer. ${ }^{57}$ In a Mendelian randomisation study, nine of the most common genotype combinations of four plasma CRP single nucleotide polymorphisms were associated with an increase in plasma CRP levels, but not with increased risk of cancers, suggesting that elevated plasma CRP does not cause cancer. ${ }^{55}$ In this study, the number of participants with a diagnosis of cancer was small, and the study design was cross-sectional. We should consider reverse causation, survival bias or other confounding factors in the relationship between plasma CRP and cancers.

This study had several limitations. First, the definition of myocardial infarction or angina, stroke, cancer, and other comorbidities was dependent on the information provided by the participants during the interview. Although trained researchers asked participants in face-to-face interviews, participants may have misunderstood the information given by physicians. Second, we were unable to assess the use of medications, such as non-steroidal anti-inflammatory drugs or corticosteroids, that could have affected plasma CRP levels. Third, we could not exclude participants with acute inflammatory diseases, such as acute viral or bacterial infection. There were no data about acute inflammatory conditions in this survey. In the participants with acute inflammatory disease, plasma CRP may not be suitable for estimation of the risk of comorbidities. Fourth, the causality could not be determined due to the cross-sectional design of this study. Fifth, we only analysed plasma CRP as an inflammatory marker. This was because IL-6 and other inflammatory cytokines were not included in the KNHANES data. Despite all these limitations, the strength of this study was that we analysed the association between plasma CRP and comorbidities using nationwide representative samples from the Korean adult population, adjusted for socioeconomic and lifestyle characteristics. Our comprehensive cross-sectional data provide additional information about the relationship between plasma CRP and comorbidities.

In conclusion, plasma CRP was positively associated with an increased risk of diabetes, dyslipidaemia and metabolic syndrome in the general population. The results of this study suggest that a low-grade inflammatory process may be related to cardiovascular risk factors. Clinicians should devote attention to glucose, lipid profile and central obesity in patients with elevated plasma CRP levels. 
Author affiliations

${ }^{1}$ Division of Rheumatology, Department of Internal Medicine, Soonchunhyang University Hospital Bucheon, Bucheon, South Korea

${ }^{2}$ Statistics and Data Center, Samsung Medical Center, Seoul, South Korea ${ }^{3}$ Division of Rheumatology, Department of Internal Medicine, National Medical Center, Seoul, South Korea

${ }^{4}$ Department of Medicine, Samsung Medical Center, Sungkyunkwan University School of Medicine, Seoul, South Korea

Contributors HJ designed this study, contributed to data collection, performed statistical analyses and drafted the manuscript. S-YB and SWK collected the data, performed statistical analyses and contributed to the interpretation of data. E-JP and JL were responsible for the conceptual development of the research and contributed to the interpretation of statistical results. HK and CHJ designed this study and critically reviewed the data. All authors have critically revised the manuscript and approved the final version for publication.

Funding The authors have not declared a specific grant for this research from any funding agency in the public, commercial or not-for-profit sectors.

Competing interests None declared.

Patient consent for publication Not required.

Ethics approval This study was approved by the Institutional Review Board of Soonchunhyang University Bucheon Hospital. Written informed consent was obtained from participants before completing the survey.

Provenance and peer review Not commissioned; externally peer reviewed.

Data availability statement Data are available in a public, open access repository.

Open access This is an open access article distributed in accordance with the Creative Commons Attribution Non Commercial (CC BY-NC 4.0) license, which permits others to distribute, remix, adapt, build upon this work non-commercially, and license their derivative works on different terms, provided the original work is properly cited, appropriate credit is given, any changes made indicated, and the use is non-commercial. See: http://creativecommons.org/licenses/by-nc/4.0/.

\section{REFERENCES}

1. Pepys MB, Hirschfield GM. C-Reactive protein: a critical update. $J$ Clin Invest 2003;111:1805-12.

2. Zacho J, Tybjaerg-Hansen A, Nordestgaard BG. C-reactive protein and all-cause mortality--the Copenhagen City Heart Study. Eur Heart J 2010;31:1624-32.

3. Lakoski SG, Cushman M, Palmas W, et al. The relationship between blood pressure and C-reactive protein in the multi-ethnic study of atherosclerosis (MESA). J Am Coll Cardiol 2005;46:1869-74.

4. Danesh J, Whincup $P$, Walker M, et al. Low grade inflammation and coronary heart disease: prospective study and updated metaanalyses. BMJ 2000;321:199-204.

5. Kaptoge S, Di Angelantonio E, Lowe G, et al. C-Reactive protein concentration and risk of coronary heart disease, stroke, and mortality: an individual participant meta-analysis. Lancet 2010;375:132-40.

6. Freeman DJ, Norrie J, Caslake MJ, et al. C-Reactive protein is an independent predictor of risk for the development of diabetes in the West of Scotland coronary prevention study. Diabetes 2002;51:1596-600.

7. Hage FG. C-Reactive protein and hypertension. J Hum Hypertens 2014:28:410-5

8. den Engelsen C, Koekkoek PS, Gorter KJ, et al. High-Sensitivity $\mathrm{C}$-reactive protein to detect metabolic syndrome in a centrally obese population: a cross-sectional analysis. Cardiovasc Diabetol 2012;11:25.

9. Deichmann M, Benner A, Waldmann V, et al. Interleukin-6 and its surrogate C-reactive protein are useful serum markers for monitoring metastasized malignant melanoma. J Exp Clin Cancer Res 2000;19:301-7.

10. Kallio R, Bloigu A, Surcel HM, et al. C-Reactive protein and erythrocyte sedimentation rate in differential diagnosis between infections and neoplastic fever in patients with solid tumours and lymphomas. Support Care Cancer 2001;9:124-8.

11. Heikkilä K, Ebrahim S, Lawlor DA. A systematic review of the association between circulating concentrations of $C$ reactive protein and cancer. J Epidemiol Community Health 2007;61:824-33.

12. Choe W-S, Choi E-K, Han K-D, et al. Association of metabolic syndrome and chronic kidney disease with atrial fibrillation: a nationwide population-based study in Korea. Diabetes Res Clin Pract 2019;148:14-22.

13. Kim J-H, Noh J, Choi J-W, et al. Association of education and smoking status on risk of diabetes mellitus: a population-based nationwide cross-sectional study. Int J Environ Res Public Health 2017; $14: 655$.

14. Kim TJ, Lee JW, Kang HT, et al. Trends in blood pressure and prevalence of hypertension in Korean adults based on the 1998-2014 KNHANES. Yonsei Med J 2018;59:356-65.

15. Kweon S, Kim Y, Jang M-jin, et al. Data resource profile: the Korea National health and nutrition examination survey (KNHANES). Int $J$ Epidemiol 2014;43:69-77.

16. Friedewald WT, Levy RI, Fredrickson DS. Estimation of the concentration of low-density lipoprotein cholesterol in plasma, without use of the preparative ultracentrifuge. Clin Chem 1972;18:499-502.

17. Grundy SM, Cleeman JI, Daniels SR, et al. Diagnosis and management of the metabolic syndrome: an American heart Association/National heart, lung, and blood Institute scientific statement. Circulation 2005;112:2735-52.

18. Allin $\mathrm{KH}$, Nordestgaard BG. Elevated C-reactive protein in the diagnosis, prognosis, and cause of cancer. Crit Rev Clin Lab Sci 2011;48:155-70.

19. Woloshin S, Schwartz LM. Distribution of C-reactive protein values in the United States. N Engl J Med 2005;352:1611-3.

20. Timpson NJ, Nordestgaard BG, Harbord RM, et al. C-Reactive protein levels and body mass index: elucidating direction of causation through reciprocal Mendelian randomization. Int $J$ Obes 2011;35:300-8.

21. Saito I. Epidemiological evidence of type 2 diabetes mellitus, metabolic syndrome, and cardiovascular disease in Japan. Circ $J$ 2012;76:1066-73.

22. Khera A, McGuire DK, Murphy SA, et al. Race and gender differences in C-reactive protein levels. J Am Coll Cardiol 2005;46:464-9.

23. Reiner AP, Beleza S, Franceschini N, et al. Genome-Wide association and population genetic analysis of C-reactive protein in African American and Hispanic American women. Am J Hum Genet 2012;91:502-12.

24. Ford ES. Body mass index, diabetes, and C-reactive protein among U.S. adults. Diabetes Care 1999;22:1971-7.

25. King DE, Mainous AG3rd, Buchanan TA, et al. C-Reactive protein and glycemic control in adults with diabetes. Diabetes Care 2003;26:1535-9.

26. Festa A, D'Agostino R Jr, Tracy RP, et al. Elevated levels of acute-phase proteins and plasminogen activator inhibitor- 1 predict the development of type 2 diabetes: the insulin resistance atherosclerosis study. Diabetes 2002;51:1131-7.

27. Mohanty P, Hamouda W, Garg R, et al. Glucose challenge stimulates reactive oxygen species (ROS) generation by leucocytes. J Clin Endocrinol Metab 2000;85:2970-3

28. Hoffman RP. Hyperglycemic endothelial dysfunction: does it happen and does it matter? J Thorac Dis 2015;7:1693-5.

29. Gelaye B, Revilla L, Lopez T, et al. Association between insulin resistance and C-reactive protein among Peruvian adults. Diabetol Metab Syndr 2010;2

30. Xu JW, Morita I, Ikeda K, et al. C-Reactive protein suppresses insulin signaling in endothelial cells: role of spleen tyrosine kinase. $\mathrm{Mol}$ Endocrinol 2007;21:564-73.

31. Vu JD, Vu JB, Pio JR, et al. Impact of C-reactive protein on the likelihood of peripheral arterial disease in United States adults with the metabolic syndrome, diabetes mellitus, and preexisting cardiovascular disease. Am J Cardiol 2005;96:655-8.

32. Devaraj S, Singh U, Jialal I. Human C-reactive protein and the metabolic syndrome. Curr Opin Lipidol 2009;20:182-9.

33. Festa A, D'Agostino R Jr, Howard G, et al. Chronic subclinica inflammation as part of the insulin resistance syndrome: the insulin resistance atherosclerosis study (IRAS). Circulation 2000;102:42-7.

34. Fröhlich M, Imhof A, Berg G, et al. Association between C-reactive protein and features of the metabolic syndrome: a population-based study. Diabetes Care 2000;23:1835-9.

35. Mahajan A, Jaiswal A, Tabassum R, et al. Elevated levels of C-reactive protein as a risk factor for metabolic syndrome in Indians. Atherosclerosis 2012;220:275-81.

36. Tamakoshi K, Yatsuya H, Kondo T, et al. The metabolic syndrome is associated with elevated circulating $\mathrm{C}$-reactive protein in healthy reference range, a systemic low-grade inflammatory state. Int J Obes Relat Metab Disord 2003;27:443-9.

37. Pickup JC, Mattock MB, Chusney GD, et al. Niddm as a disease of the innate immune system: association of acute-phase reactants and interleukin-6 with metabolic syndrome X. Diabetologia 1997;40:1286-92. 
38. Kang ES, Kim HJ, Ahn CW, et al. Relationship of serum high sensitivity C-reactive protein to metabolic syndrome and microvascular complications in type 2 diabetes. Diabetes Res Clin Pract 2005:69:151-9.

39. Pannacciulli N, Cantatore FP, Minenna A, et al. C-Reactive protein is independently associated with total body fat, central fat, and insulin resistance in adult women. Int J Obes Relat Metab Disord 2001;25:1416-20.

40. Ridker PM, Pare G, Parker A, et al. Loci related to metabolicsyndrome pathways including LEPR,HNF1A, IL6R, and GCKR associate with plasma C-reactive protein: the Women's Genome Health Study. Am J Hum Genet 2008;82:1185-92.

41. Sattar N, McConnachie A, Shaper AG, et al. Can metabolic syndrome usefully predict cardiovascular disease and diabetes? outcome data from two prospective studies. Lancet 2008;371:1927-35.

42. Lakka HM, Laaksonen DE, Lakka TA, et al. The metabolic syndrome and total and cardiovascular disease mortality in middle-aged men. JAMA 2002;288:2709-16.

43. Libby P, Ridker PM. Inflammation and atherosclerosis: role of C-reactive protein in risk assessment. Am J Med 2004;116 Suppl 6A:9S-16.

44. Pepys MB, Hirschfield GM. C-Reactive protein and atherothrombosis. Ital Heart J 2001;2:196-9.

45. Sesso HD, Buring JE, Rifai N, et al. C-Reactive protein and the risk of developing hypertension. JAMA 2003;290:2945-51.

46. Ridker PM, Rifai N, Rose L, et al. Comparison of C-reactive protein and low-density lipoprotein cholesterol levels in the prediction of first cardiovascular events. N Engl J Med 2002;347:1557-65.

47. Ross R. Atherosclerosis--an inflammatory disease. N Engl J Med 1999;340:115-26.
48. Paffen E, DeMaat MPM. C-Reactive protein in atherosclerosis: a causal factor? Cardiovasc Res 2006;71:30-9.

49. Pearson TA, Mensah GA, Alexander RW, et al. Markers of inflammation and cardiovascular disease: application to clinical and public health practice: a statement for healthcare professionals from the centers for disease control and prevention and the American heart association. Circulation 2003;107:499-511.

50. Ridker PM, Cook N. Clinical usefulness of very high and very low levels of $\mathrm{C}$-reactive protein across the full range of Framingham risk scores. Circulation 2004;109:1955-9.

51. Siemes C, Visser LE, Coebergh JW, et al. C-Reactive protein levels, variation in the C-reactive protein gene, and cancer risk: the Rotterdam study. J Clin Oncol 2006;24:5216-22.

52. Erlinger TP, Platz EA, Rifai N, et al. C-Reactive protein and the risk of incident colorectal cancer. JAMA 2004;291:585-90.

53. Trichopoulos D, Psaltopoulou T, Orfanos P, et al. Plasma C-reactive protein and risk of cancer: a prospective study from Greece. Cancer Epidemiol Biomarkers Prev 2006;15:381-4.

54. Allin KH, Bojesen SE, Nordestgaard BG. Baseline C-reactive protein is associated with incident cancer and survival in patients with cancer. J Clin Oncol 2009;27:2217-24.

55. Allin $\mathrm{KH}$, Nordestgaard BG, Zacho J, et al. C-Reactive protein and the risk of cancer: a Mendelian randomization study. J Natl Cancer Inst 2010;102:202-6.

56. Ito Y, Suzuki K, Tamakoshi K, et al. Colorectal cancer and serum C-reactive protein levels: a case-control study nested in the JACC study. J Epidemiol 2005;15(Suppl 2):S185-S189.

57. Rifai N, Buring JE, Lee I-M, et al. Is C-reactive protein specific for vascular disease in women? Ann Intern Med 2002;136:529-33. 